\title{
RESEARCH
}

Open Access

\section{Use of patient specific 3D printed neurovascular phantoms to simulate mechanical thrombectomy}

\author{
Kelsey N. Sommer ${ }^{1,2^{*}}$ (D), Mohammad Mahdi Shiraz Bhurwani ${ }^{1,2}$, Vincent Tutino ${ }^{2,3,4}$, Adnan Siddiqui ${ }^{2,3}$,
} Jason Davies ${ }^{2,3,5}$, Kenneth Snyder ${ }^{2,3}$, Elad Levy ${ }^{2,3}$, Maxim Mokin ${ }^{6}$ and Ciprian N. Ionita ${ }^{1,2,3}$

\begin{abstract}
Background: The ability of the patient specific 3D printed neurovascular phantoms to accurately replicate the anatomy and hemodynamics of the chronic neurovascular diseases has been demonstrated by many studies. Acute occurrences, however, may still require further development and investigation and therefore we studied acute ischemic stroke (AIS). The efficacy of endovascular procedures such as mechanical thrombectomy (MT) for the treatment of large vessel occlusion (LVO), can be improved by testing the performance of thrombectomy devices and techniques using patient specific 3D printed neurovascular models.

Methods: 3D printed phantoms were connected to a flow loop with physiologically relevant flow conditions, including input flow rate and fluid temperature. A simulated blood clot was introduced into the model and placed in the proximal Middle Cerebral Artery (MCA) region. Clot location, composition, length, and arterial angulation were varied and MTs were simulated using stent retrievers. Device placement relative to the clot and the outcome of the thrombectomy were recorded for each situation. Digital subtraction angiograms (DSA) were captured before and after LVO simulation. Recanalization outcome was evaluated using DSA as either 'no recanalization' or 'recanalization'. Forty-two 3DP neurovascular phantom benchtop experiments were performed.
\end{abstract}

Results: Clot angulation within the MCA region had the most significant impact on the MT outcome, with a $p$ value of 0.016 . Other factors such as clot location, clot composition, and clot length correlated weakly with the MT outcome.

Conclusions: This project allowed us to gain knowledge of how such characteristics influence thrombectomy success and can be used in making clinical decisions when planning the procedure and selecting specific thrombectomy tools and approaches.

Keywords: Mechanical thrombectomy, 3D printing, Large vessel occlusion, Thrombolysis in cerebral infarction

\footnotetext{
* Correspondence: kelseyso@buffalo.edu

'Department of Biomedical Engineering, University at Buffalo, Buffalo, NY 14228, USA

${ }^{2}$ Canon Stroke and Vascular Research Center, University at Buffalo, Buffalo, NY 14208, USA

Full list of author information is available at the end of the article
}

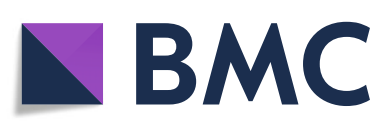

(c) The Author(s). 2021 Open Access This article is licensed under a Creative Commons Attribution 4.0 International License, which permits use, sharing, adaptation, distribution and reproduction in any medium or format, as long as you give appropriate credit to the original author(s) and the source, provide a link to the Creative Commons licence, and indicate if changes were made. The images or other third party material in this article are included in the article's Creative Commons licence, unless indicated otherwise in a credit line to the material. If material is not included in the article's Creative Commons licence and your intended use is not permitted by statutory regulation or exceeds the permitted use, you will need to obtain permission directly from the copyright holder. To view a copy of this licence, visit http://creativecommons.org/licenses/by/4.0/. The Creative Commons Public Domain Dedication waiver (http://creativecommons.org/publicdomain/zero/1.0/) applies to the data made available in this article, unless otherwise stated in a credit line to the data. 


\section{Background}

Three-Dimensional printing (3DP) offers the ability to build geometrically-accurate patient-specific vascular phantoms/models that can aid clinical decision making, including treatment planning [1]. In addition, these phantoms may be used for benchtop experimentation, device testing, and physiological simulations for hemodynamics investigation and complex fluid-device structure interactions assessments [2-5]. Current multimaterial printers replicate complex human vascular anatomy into a photopolymer replica within a few tens of microns accuracy, using materials that mimic vascular mechanical properties, thus allowing realistic simulations of endovascular interventions [6, 7]. Use of these phantoms, to practice various approaches and procedures shows promise as a method to optimize interventional outcomes and reduce the rate of peri-procedural complications.

3D printing has shown much promise in simulating vascular procedures with chronic conditions associated to them including ischemia, myocardial infarction, abdominal aortic aneurysms, and arteriovenous malformation [7-11]. Use of these phantoms to practice various approaches has been proven as a method to improve interventional outcomes, reduce the risk of periprocedural complications, and optimize treatment planning. The ability to mimic the arterial wall mechanical properties such as compliance and stiffness [3, 4, 12-14] in combination with programmable pumps to replicate cardiac waveforms and controlled outflow systems that mimic the capillary resistance $[15,16]$, allows for creation of comprehensive systems that provide means to simulate the local and global hemodynamics.

On the other hand, simulation of acute conditions including acute ischemic stroke (AIS) from large vessel occlusion (LVO) using 3D printed patient specific phantoms has not been fully investigated. These kinds of studies would be beneficial in providing insight to the clinicians regarding the various techniques and devices that are used for acute treatment of stroke which affects nearly 700,000 people in the United States annually. Often, the cause of these strokes is a lack of blood flow due to an arterial LVO in need of endovascular revascularization using stent retriever mechanical thrombectomy (MT) [17, 18]. During these procedures a retrievable device is deployed across the clot which becomes entrapped within the wiring of the device and is subsequently removed by retrieving the device. Stent retriever thrombectomy is currently recommended in patients with AIS from LVO. The success of thrombectomy is graded using Thrombolysis in Cerebral Infarction (TICI) scale which ranges from 0 (full occlusion) to 3 (no occlusion). Recanalization is the main factor that determines whether the treatment method of thrombectomy of AIS patients with LVO produced a good treatment outcome $[19,20]$. If successful recanalization is achieved, the patient is $4-5$ times more likely to recover with minimal disability after stroke.

For this study we propose to develop patient specific 3D printed models which allow AIS simulation and subsequent mechanical thrombectomy while using flow conditions relevant to cerebral hemodynamics. Using this setup, we also propose to study how variants, such as clot consistency, location and local geometry affect the efficacy of endovascular procedures for the treatment of LVOs. This type of study could add significant knowledge in regards to MT technique comparisons [14, 21, 22].

\section{Methods}

\section{Patient specific model design}

This study was approved by the IRB at University at Buffalo. We used retrospectively-collected data of patients who underwent CT-angiography and had a lesion free main cerebral vasculature. Patients underwent 320- detector row CT angiography (Aquilion ONE, Canon Medical Systems, Tustin, CA). The basilar arteries, internal carotid, vertebral, as well as the Circle of Willis, middle cerebral arteries (MCA), anterior cerebral arteries (ACA), and posterior cerebral arteries (PCA) were segmented using a Vitrea workstation (Vital Images, Minnetonka, MN) with a voxel size of $0.625 \times 0.625 \times 0.5 \mathrm{~mm}$ and a slice thickness of $0.5 \mathrm{~mm}$. Stereolithographic (STL) files were saved of the patient geometry and imported in Autodesk Meshmixer, an advanced mesh manipulation software (San Rafael, California). The neurovascular section of the phantom contains arteries distal to the external carotid artery bifurcation, extending to the second bifurcation in the middle cerebral, and anterior communicating arteries. For this vascular domain the vessel diameters ranged from approximately 2 $\mathrm{mm}$ to $5 \mathrm{~mm}$, properly correlating to the human anatomy [23].

The phantom manufacturing process including the 3D mathematical operators used to design the phantom, have been explained in full detail in previous work [2, 5, 24, 25] and design steps will be only briefly described (Fig. 1). Within Meshmixer, lumen segmentation artifacts were removed and a minimal smoothing process reduced the number of artifacts while maintaining the overall geometry of the vasculature. A base designed in SolidWorks (SolidWorks Corp., Waltham, MA) was appended to the vasculature as a support structure to provide stability to the phantom during the benchtop flow experimentation. In addition, the ICA segment between the carotid siphon and ophthalmic artery segment was either 


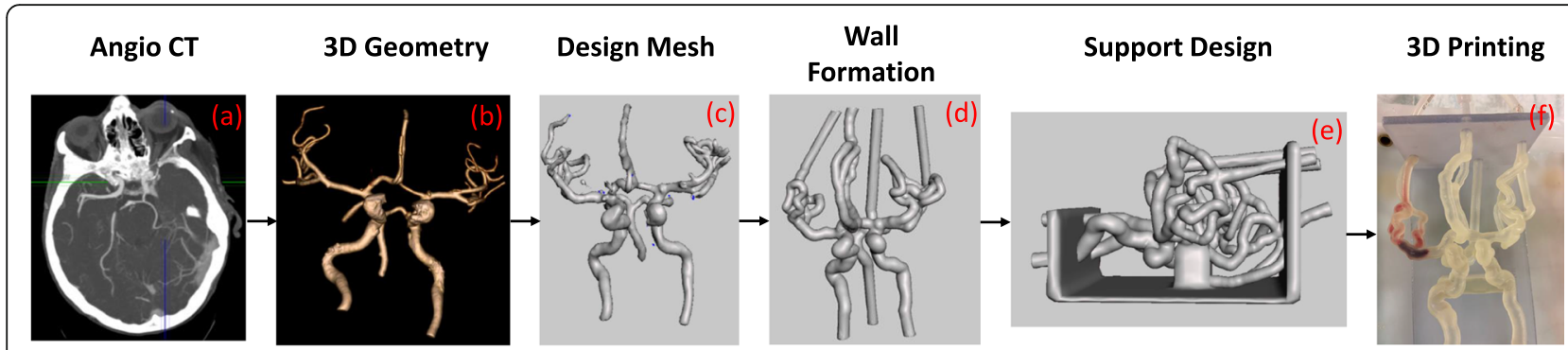

Fig. 1 Flow chart of images describing the manufacturing process for a patient specific phantom of the Circle of Willis. a An Angio CT image is acquired of the neurovasculature. $\mathbf{b}$ The neurovasculature is segmented out from the rest of the brain tissue and a 3D geometry is created. $\mathbf{c} A$ 3D mesh of triangular vertices is created within Autodesk Meshmixer. $\mathbf{d}$ The mesh is made a solid geometry and hollowed out for the creation of vessel lumens and a (e) support structure holds in place the vessels. Arrow pointing to hardened support material to reduce vessel sagging. $\mathbf{f}$ The model is 3D printed in Stratasys Tango+ material to simulate the vascular compliance and is ready to be connected to a flow loop for simulation studies

supported or reinforced by using a hardened material (Fig. 1(e) arrow) to reduce any sagging along the curvature of the vessel for proper device navigation. The phantom was 3D printed in a soft material, Stratasys Tango+ (Stratasys, Eden Prairie, MN) to replicate the neurovascular wall elasticity [12].

Optimal post-print processing of the inner artery lumen to achieve realistic device artery surface interactions, a friction analysis was conducted in a previous study [12, 26] Using their findings, we implemented a sodium hydroxide solution to etch the rough inner surfaces followed by coating with HidroMed (AdvanSource Biomaterials Wilmington, MA). Wall thickness and material composition were both tested to replicate the compliance of the neurovasculature. A compliance chamber was developed to measure changes in vessel diameter under pressures ranging from 0 to $210 \mathrm{mmHg}$ while the vessels were submerged in body temperature water to simulate physiological conditions. The results obtained concluded that Tango+ with a $1 \mathrm{~mm}$ thickness and 4.5 $\mathrm{mm}$ diameter was the only material to exhibit a compliance close to the healthy range $(0.08-0.12$ $\mathrm{mm} 2 / \mathrm{mmHg}$ ) of $0.075 \mathrm{~mm} 2 / \mathrm{mmHg}$.

The accuracy of the $3 \mathrm{D}$ printed models were also tested within another study performed within our group prior to this experimentation [4]. The centerlines from both of the CCTA images of the patient and the phantom were generated within Mimics Research (Materialize, Plymouth, MI) and the minimum diameter, maximum diameter, best fit diameter, crosssectional area, and tortuosity were calculated. It was concluded that the phantom diameter measurements were within $1 \mathrm{~mm}$ of the patient images on average and the tortuosity had a very small average difference. This verifies that our 3D printed phantoms created in an elastic material are maintaining the threedimensional geometry.

\section{Benchtop flow experimentation}

Phantoms were connected to a flow loop with a simulated physiologically relevant input flow rate of the carotid artery and fluid temperature of 37 degrees Celsius (Fig. 2) [27]. We maintained the temperature of the fluid within the flow loop to be consistently at body temperature using an Anova sous vide (Anova Applied Electronics, Inc. San Francisco, CA) as the Nitinol used in the clot retriever devices is strongly dependent on temperature. Standard digitally subtracted angiograms (Canon Medical Systems Corp., Tustin, CA) were taken with a Canon Infix $\mathrm{C}$-arm prior to insertion of the clot and medical devices. DSA images were obtained at 10 frames/sec at system-selected parameters of $\mathrm{kV}$ and $\mathrm{mA}$. Fresh clots were prepared following the methods presented by Duffy, et.al [28].. Clot type D (40\% red blood cells, calcium chloride) and type $\mathrm{G}$ (pure fibrin, calcium chloride) were created.

Clots were then measured into pieces of varying lengths between $5 \mathrm{~mm}$ and $25 \mathrm{~mm}$ for the experimentation.

A clot was introduced into the model and placed anywhere in the M1 or M2. The 3D printed patient specific models connected to a flow loop is shown in Fig. 3. A guide catheter was inserted into the internal carotid artery (ICA) of the 3D printed phantom on the side of occlusion. The guide catheter provides support for the microcatheter which was next inserted to navigate to the location of the occlusion. The stent retriever was deployed across the simulated blood clot at the occlusion site. We used both Trevo XP (Stryker Corporation, Kalamazoo, MI) and Solitaire X (Medtronic, Dublin, Ireland) stent retrievers. Stent retriever diameters ranged from 4 to $6 \mathrm{~mm}$ and did not influence the experimental outcome so we did not include those results in this study. A stent retriever thrombectomy was then simulated with the following parameters studied: angulation (angle of the vasculature in which the clot is placed) (Fig. 4), clot length (before and after insertion), clot morphology (D/ 


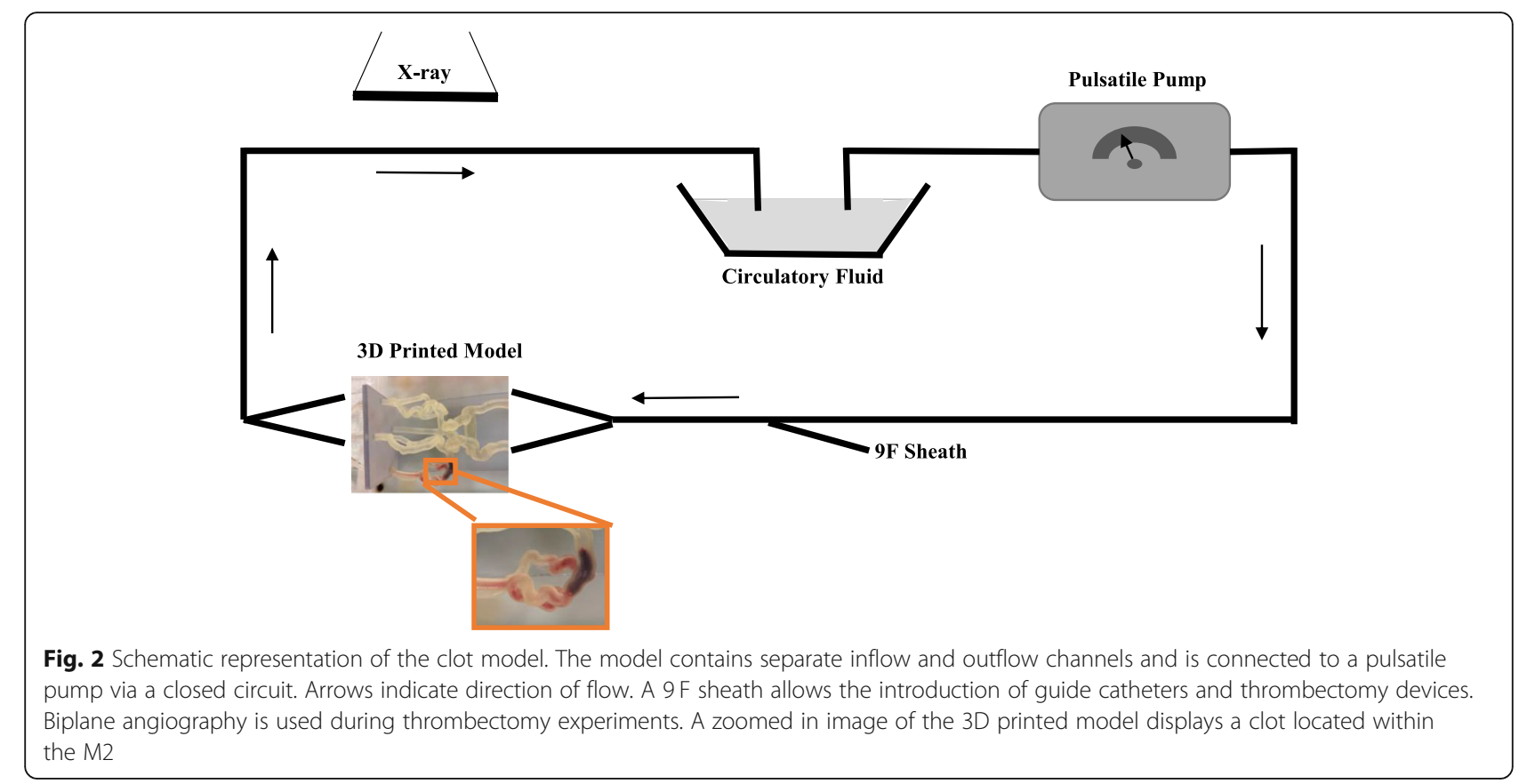

$\mathrm{G}$ clots), clot location within the device and within the vasculature, and treatment approach (standard thrombectomy with/without aspiration). DSA was performed prior to thrombectomy to confirm adequate occlusion and after thrombectomy to document angiographic outcome. DSA was graded according to the TICI scale. TICI $2 \mathrm{~b} / 3$ was considered "successful" recanalization, TICI 02a was consider "unsuccessful" recanalization.

\section{Statistical analysis}

A $p$-value $<0.05$ was considered indicative of a statistically significant difference. A multi-variable regression model was performed on the entirety of the data with the experimental outcome as the $y$-variable and the clot angulation within the vasculature $\left(\mathrm{x}_{1}\right)$, initial clot length $\left(\mathrm{x}_{2}\right)$, clot composition $\left(\mathrm{x}_{3}\right)$, clot location within device $\left(x_{4}\right)$, and clot location within vasculature $\left(x_{5}\right)$ as the $x$ variables. Estimated coefficients $\left(\beta_{0}, \beta_{1}, \beta_{2}, \beta_{3}, \beta_{4}, \beta_{5}\right), p$ values and odds ratios were determined. Odds ratios were determined by binarizing the results as follows: clot angulation $\left(>=120^{\circ},<120^{\circ}\right)$; clot length $(>12 \mathrm{~mm},<=12$ $\mathrm{mm}$ ); clot composition (hard, soft); clot location in device (mid, proximal/distal); clot location in vasculature (M1/M2).
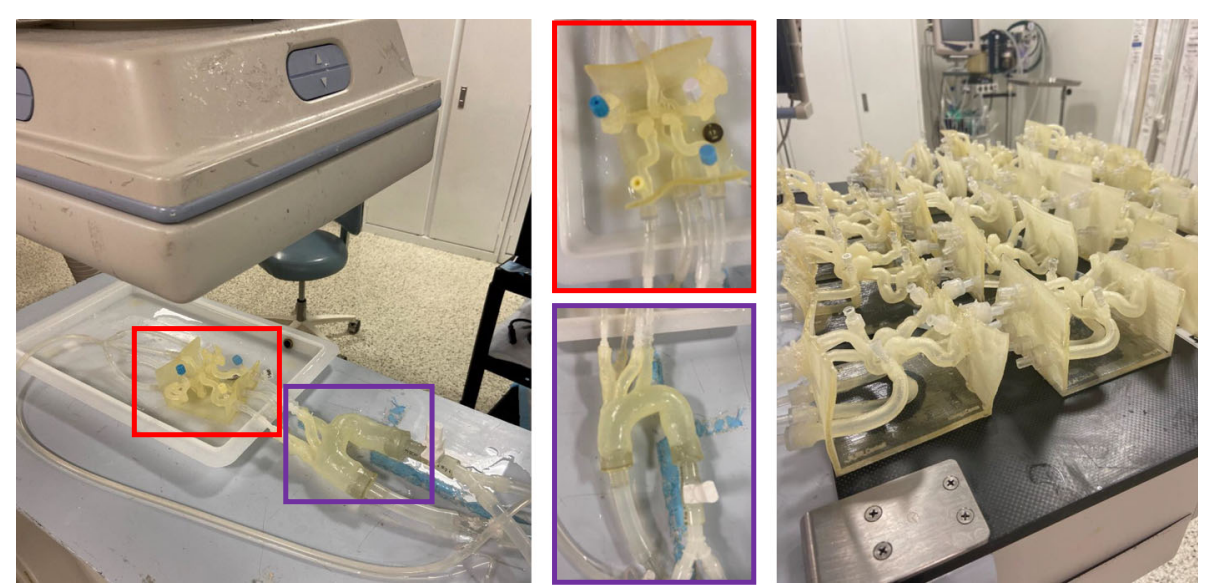

Fig. 3 The 3D printed patient specific Circle of Willis is connected to a flow loop. (Red) The patient specific neurovasculature and (Purple) a standard aortic arch are highlighted. 20 different patient specific models have been printed. A clot is introduced into the proximal MCA and tests the effectiveness of stent retriever thrombectomy with $\mathrm{TICl}$ scoring system in patients with absent or robust collaterals of the circle of Willis using a conventional vs. BGC 


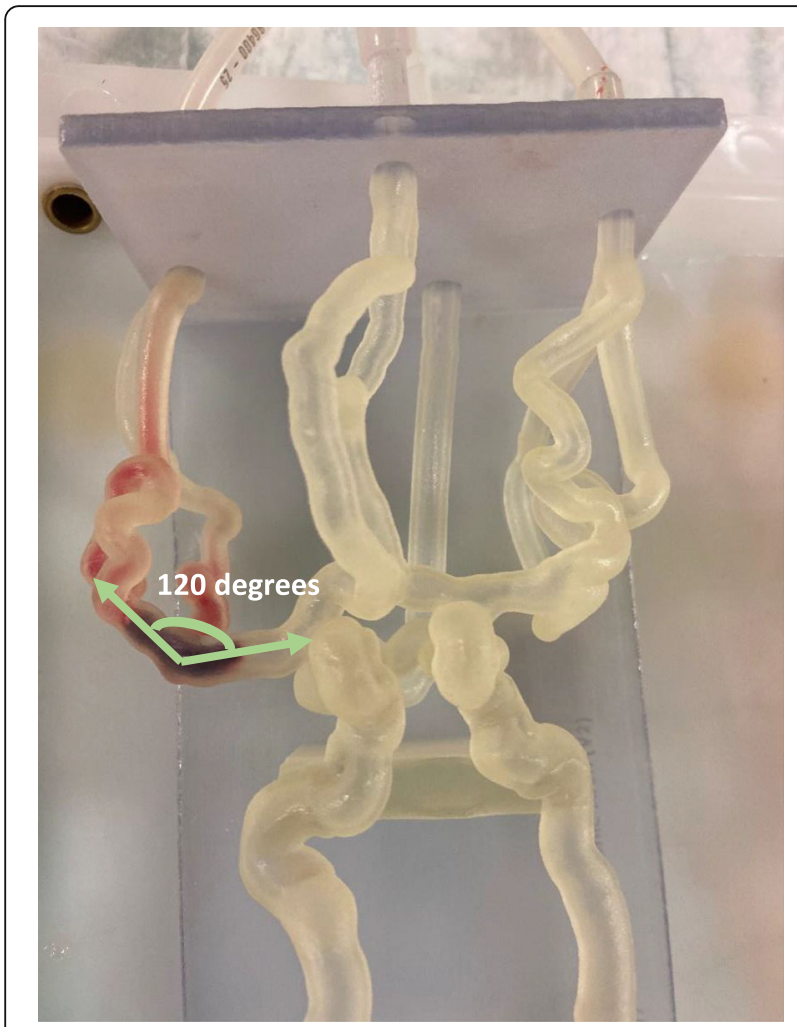

Fig. 4 The angulation of the clot within the vasculature was measured as an experimental variable to determine if it has effect on the experimental outcome

\section{Results}

Using these phantoms, angiograms were captured before recanalization, showing the extent of the thrombus, and after the thrombectomy to determine the recanalization outcome. Figure 5 displays the change in blood flow before and after the stent retriever has been deployed. Figure 6 depicts a montage of the contrast flowing through a 3D printed model after both an unsuccessful and a successful mechanical thrombectomy simulated procedure.

The experimental outcome was recorded for each experiment as either recanalization or no recanalization (Fig. 7). Based on our results, 29 of the 42 benchtop experiments were successful.

The results for the 42 experiments have been analyzed based on the parameters we changed within the study to determine their single variable significance to experimental outcome (Table 1).

Based on these experimental parameters, the 'Clot Angulation' proved to be the only experimental variable of 'Significance' with a $p$-value of 0.016 . Table 1 also displays the means with $95 \%$ confidence intervals of each experimental variable for both the successful and unsuccessful experimental outcomes.
Based on the multi-variable regression model used, estimated regression coefficients were output for each experimental independent variable to determine whether they have an impact on the experimental outcome (Table 2). All estimated regression coefficients were very close to zero which implies that all the experimental variables have little impact on the experimental outcome.

\section{Discussion}

3D printing offers a unique opportunity to build geometrically accurate patient specific vascular phantoms that can be used for benchtop testing, flow simulations, treatment planning, device testing, and physiological simulations. Patient specific vascular models engineered through additive manufacturing can be used to visualize complex anatomical structures and simulate device deployment. Previous studies have used phantoms with stiff photopolymers that lack the compliance of the vasculature which is crucial for properly simulating the physiology within the vascular anatomy [15, 29-31]. To capture the compliant nature of the vasculature, flexible photoresins such as the Stratasys Tango family (Stratasys, Eden Prairie, MN) and the Visijet 3D Systems family (3D Systems, Rock Hill, SC) is needed and has been tested under previous investigation [26]. With the preservation of the hemodynamics within the vasculature by means of compliance, stiffness and pressure simulations, 3D printed vascular models can accurately depict the fluid mechanics within the human anatomy [32-34].

We performed a comprehensive study using 3D printed patient specific neurovascular phantoms which may allow for a relatively simple means to test devices, fine tune procedures, and train surgeons. This project employs a novel approach that combines 3D model manufacturing technology with the ability to generate patient-specific anatomical variants for accurate simulation of real-world clinical scenarios of AIS from LVO treated with mechanical thrombectomy.

Through the evaluation of controlled changing parameters within our experimental setup, we were able to demonstrate the use of 3DP vascular phantoms to simulate acute complications such as AIS. In addition, we design a set of tests to determine single variable and multivariable significance on the experimental outcome using variants that may affect the MT such as clot composition, location, geometry and length. The local geometry, namely the clot angulation, proved to be the single significant experimental variable, $p$-value of 0.016 , that affects the experimental thrombectomy outcome. Acute angles may prevent the device from fully engaging the clot, and thus reduce the thrombectomy effectiveness. Clot length within our testing range, $5 \mathrm{~mm}$ to 25 


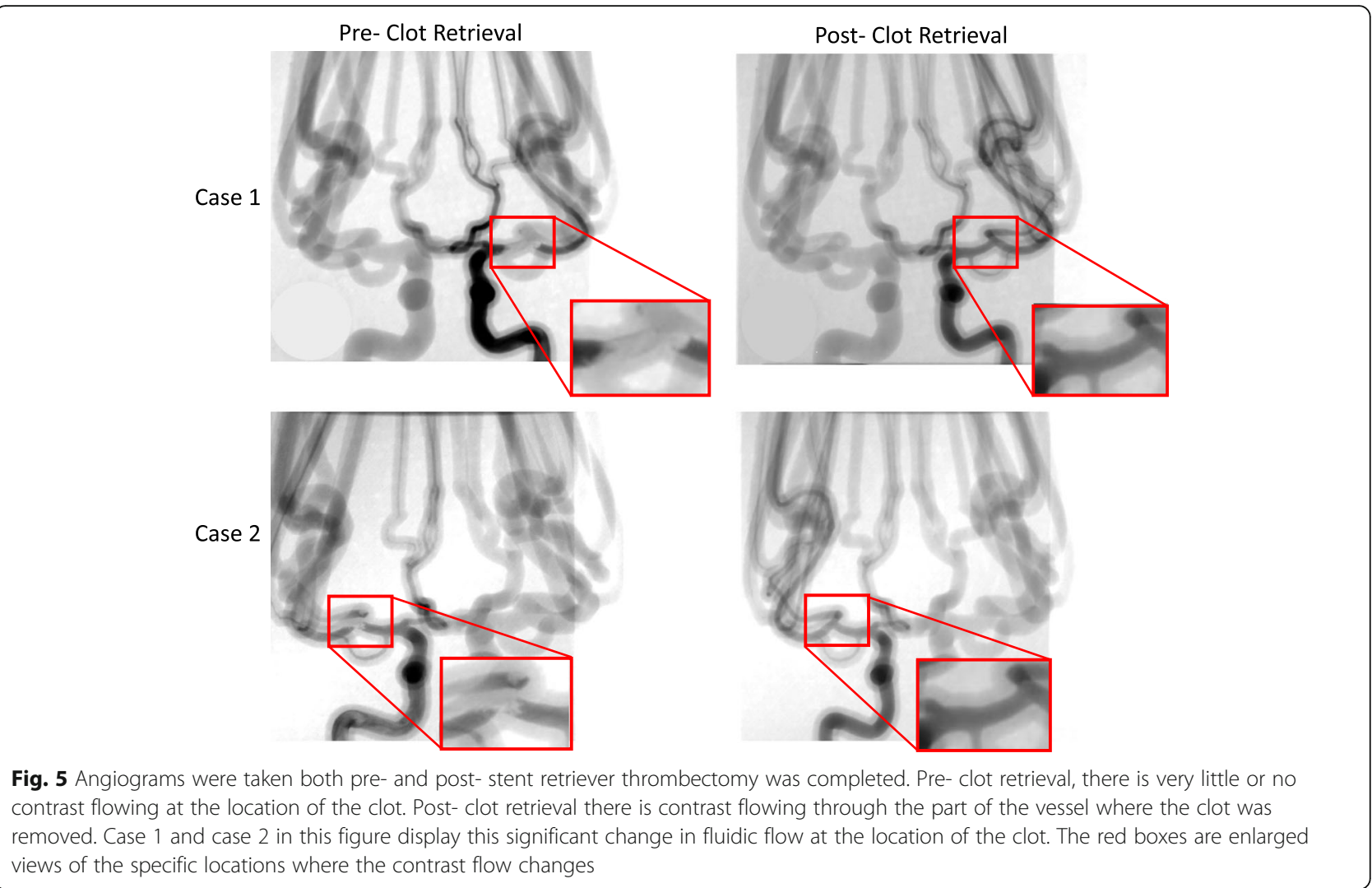

$\mathrm{mm}$, was not a significant factor which might also be due to the fact that the devices used were between 30 and $40 \mathrm{~mm}$ long and enclosed fully the device. Also, the longer clots tend to stop more proximal in the circle of Willis which made them easier to access and remove. This last aspect also ties into the location analysis, we did not see a significant correlation between the location within the vasculature and MT efficacy.

There are a few phantom design related limitations to our study. 3D printing based phantoms are subject to CT imaging errors including scan errors due to patient motion, blooming due to calcification, and a reduction in image accuracy with the 3DP

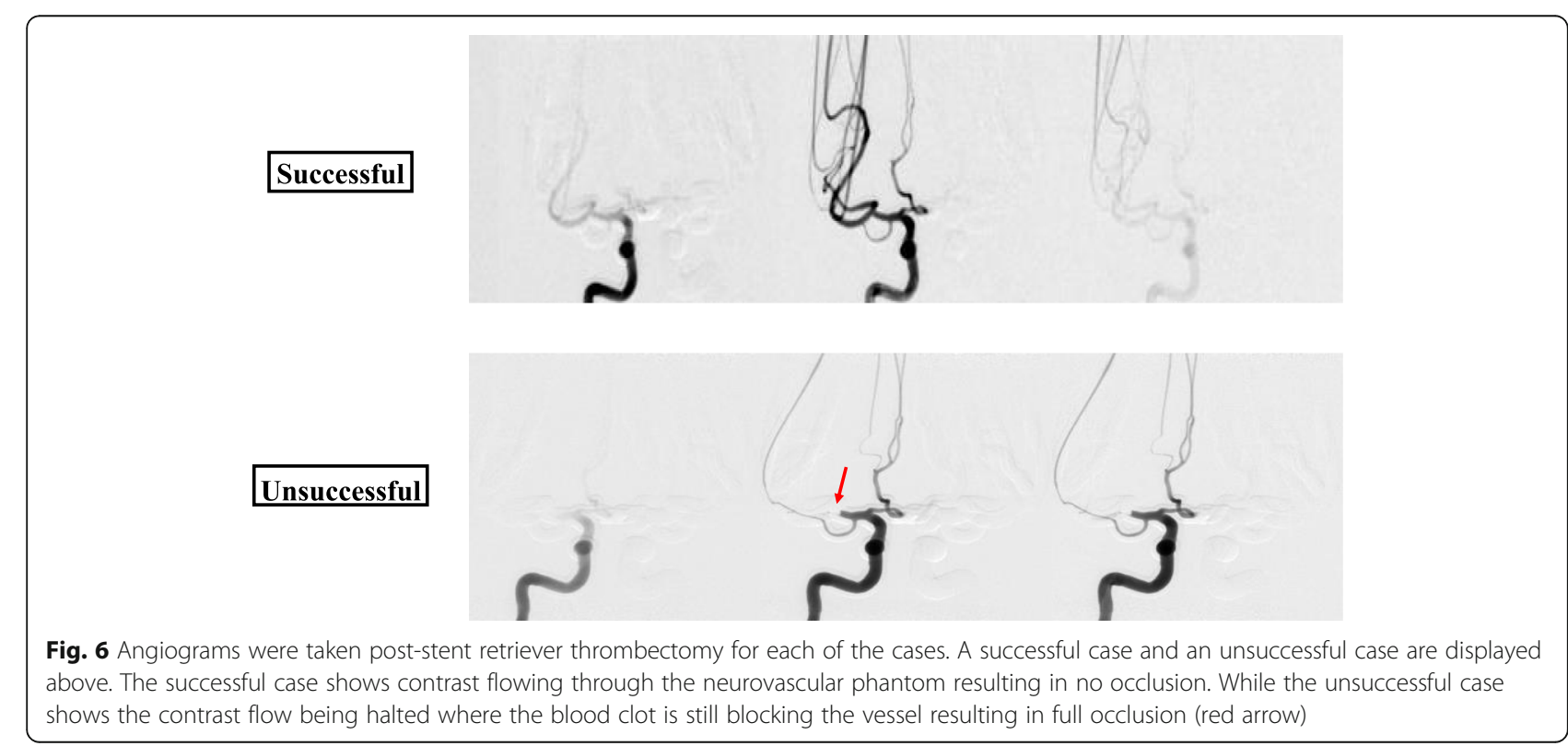




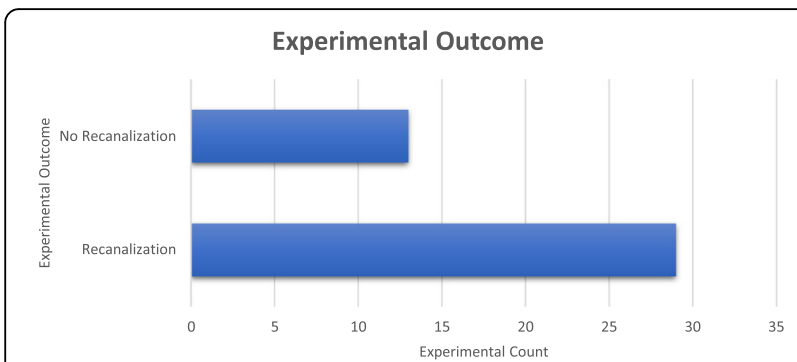

Fig. 7 An experimental outcome was determined for each of the 42 benchtop experiments performed as 'No Recanalization' or 'Recanalization'

resolution of $200 \mu \mathrm{m}$ surpassing the spatial resolution of the CCTA of $630 \mu \mathrm{m}$. Since most of the neurovasculature are between 2 to 4-mm diameter, small segmentation errors can result in significant changes in the hemodynamics. Involving the segmentation process, there may have been some errors in defining the vessel wall boundaries with high accuracy; however, we cross-validated this process between two users to avoid significant errors. Also, in the process of segmentation artifact elimination, we sculpted the mesh within Autodesk Meshmixer manipulating single triangular vertices, which might have created slight geometric alterations. Additionally, with the models being printed in an elastic material, this allows for deformations to occur within the printing process which may affect the accuracy of the benchtop testing over time.

Other limitations are related to the proposed benchtop system. Since the experimental implementation was challenging due to accumulation of iodinated contrast and clot fragments we did not use a standard water glycerol mixture to simulate blood viscosity. This is a limitation of our study since use of water only as a working fluid could potentially change the fluid dynamics of the system especially at the occlusion location, due to the complexity of the simulation and the abundance of unknown variables being tested. We heated the water to body temperature as the nitinol within the thrombectomy devices reacts best at this temperature. However; the clot to vessel wall interaction may introduce error into the system as the composition of both surfaces vary from that of the human blood clots and vessels.

As an in vitro-study our approach has some limitations but also benefits which may not be replicated with other in-vitro models or animal models. The limitations include, only partial reproducibility of the biomechanical properties of the arterial network and device-clot-blood interaction and missing the effect of distal microvasculature which could affect the hemodynamics. On the other hand, the 3D printing models allow studies to be performed in an identical replica of the human vasculature, using patients who underwent mechanical thrombectomies with known outcomes. This fact may become far more relevant for device testing then animal models or idealized models since it allows not only to research generic device behavior in human like geometries but also optimize this kind of a treatment.. There is also great value of this benchtop setup as a training device for interventionalists. Before training on a human patient, these patient specific 3DP printed models incorporated into our benchtop set up allow for techniques such as stent retriever deployment, catheter insertion, and image-guided device navigation. With the incorporation of vessel elasticity and compliance parameters, these models provide a novel approach in simulated patient specific vascular studies.

\section{Conclusions}

The main advantage of using this in vitro model of thrombectomy is that it provides a highly controlled environment where only a single variable (such as angulation of MCA or clot length) or treatment approach can be changed at a time. This project allowed us to gain knowledge of how such characteristics influence thrombectomy success can be used in making clinical decisions when planning the

Table 1 Single Variable Statistical Tests of Significance were determined for each of the following experimental variables: clot angulation, clot length, clot composition, clot location in device, and clot location in vasculature. Either a student t-test or a chisquared test were performed to output the $p$-value for each experimental variable. Means for both successful and unsuccessful cases are presented with $\pm 95 \%$ confidence

\begin{tabular}{|c|c|c|c|c|}
\hline Experimental Variable & Statistical Test & $\begin{array}{l}\text { Mean } \\
\text { (Successful) }\end{array}$ & $\begin{array}{l}\text { Mean } \\
\text { (Unsuccessful) }\end{array}$ & $P$-Value \\
\hline Clot Angulation & Student T-test & $118.10 \pm 19.44^{\circ}$ & $153.46 \pm 17.37^{\circ}$ & 0.016 \\
\hline Clot Length & Student T-test & $16.76 \pm 2.64 \mathrm{~mm}$ & $15.38 \pm 3.68 \mathrm{~mm}$ & 0.557 \\
\hline Clot Composition & Chi-Squared Test & N/A & N/A & 0.115 \\
\hline Clot Location in Device & Chi-Squared Test & N/A & N/A & 0.196 \\
\hline Clot Location in Vasculature & Chi-Squared Test & N/A & N/A & 0.579 \\
\hline
\end{tabular}


Table 2 Multi-variable statistical analysis was performed on the experimental data in which clot angulation $\left(\mathrm{x}_{1}\right)$, clot length $\left(\mathrm{x}_{2}\right)$, clot composition $\left(x_{3}\right)$, clot location in device $\left(x_{4}\right)$, and clot location in vasculature $\left(x_{5}\right)$ were allocated to be the model predictors.

Regression coefficients, $R^{2}$, adjusted $R^{2}$, and an overall $p$-value were output from the model

\begin{tabular}{lllll}
\hline Model: $y=\beta_{0}+x_{1} \beta_{1}+x_{2} \beta_{2}+x_{3} \beta_{3}+x_{\mathbf{4}} \beta_{\mathbf{4}}+x_{\mathbf{5}} \beta_{5}$ & & & \\
\hline Predictor & Regression Coefficient & Estimate & P-Value & Odds Ratio (95\% Confidence Intervals) \\
\hline Constant & $\beta_{0}$ & 1.005 & 0.0002 & \\
Clot Angulation $\left(x_{1}\right)$ & $\beta_{1}$ & -0.140 & 0.005 & $0.170(0.032-0.905)$ \\
Clot Length $\left(\mathbf{x}_{\mathbf{2}}\right)$ & $\beta_{2}$ & 0.176 & 0.820 & $1.828(0.457-7.315)$ \\
Clot Composition $\left(x_{\mathbf{3}}\right)$ & $\beta_{3}$ & -0.183 & 0.369 & $1.300(0.275-6.137)$ \\
Clot Location in Device $\left(\mathbf{x}_{\mathbf{4}}\right)$ & $\beta_{4}$ & -0.008 & 0.179 & $0.885(0.232-3.380)$ \\
Clot Location in Vasculature $\left(\mathbf{x}_{\mathbf{5}}\right)$ & $\beta_{5}$ & -0.004 & 0.664 & $1.714(0.452-6.506)$ \\
\hline
\end{tabular}

Odds ratios were determined by binarizing the results as follows: clot angulation ( $>=120^{\circ},<120^{\circ}$ ); clot length ( $>12 \mathrm{~mm},<=12 \mathrm{~mm}$ ); clot composition (hard, soft); clot location in device (mid, proximal/distal); clot location in vasculature (M1/M2)

procedure and selecting specific thrombectomy tools and approaches.

\section{Abbreviations}

3DP: Three-Dimensional Printing; MT: Mechanical Thrombectomy; AIS: Acute Ischemic Stroke; LVO: Large Vessel Occlusion; MCA: Middle Cerebral Artery; DSA: Digital Subtraction Angiography

\section{Acknowledgements}

This work was supported by R21 NS109575-01 as well as equipment from Stratasys (Eden Prairie, MN) and Canon Medical Systems (Otawara, Japan).

\section{Authors' contributions}

KS drafted the manuscript. All authors aided in the revision of the manuscript. AS, KS, JD and EL provided the patients for us to obtain the CCTA data. Cl initiated the development of a method to create 3D printed patient specific vascular models. KS advanced the workflow of 3D printing of patient specific vascular models, mechanical thrombectomy experimentation, and analyzed and interpreted the data obtained in this study. MM aided in the data analysis and interpretation. The authors read and approved the final manuscript.

\section{Authors' information}

Kelsey N. Sommer - Kelsey N. Sommer is a third year PhD student in the group of Dr. Ciprian N. Ionita at the University at Buffalo, Canon Stroke and Vascular Research Center. This group is a very active participant at SPIE Medical Imaging for the last 20 years with nearly 100 presentations and posters and have received various awards for scientific achievements. Kelsey has given presentations at eight international conferences, including SPIE Medical Imaging and the RSNA Annual Meeting, and earned a Certificate of Merit at the latter.

Mohammad Mahdi Shiraz Bhurwani - Mohammad Mahdi Shiraz Bhurwani is a third year PhD student in the group of Dr. Ciprian N. Ionita at the University at Buffalo, Canon Stroke and Vascular Research Center. He has given presentations at five international conferences, including SPIE Medical Imaging and the RSNA Annual Meeting.

Maxim Mokin - Dr. Maxim Mokin is an endovascular neurosurgeon at Tampa General Hospital and associate professor at The University of South Florida, Tampa, Florida. He received his medical degree from Omsk State Medical Academy and has been practicing for almost 20 years. He completed his neurology residency and fellowships in vascular neurology and neuroendovascular surgery at The University at Buffalo.

Vincent Tutino - Dr. Vincent Tutino is a Research Assistant Professor at the University at Buffalo. He has been extensively trained in translational research and has a strong background in diagnostics development and computational methods in medical research. He is also an entrepreneur, and has successfully spun-off startup companies in the Buffalo, NY area. He is acting President and CEO of Neurovascular Diagnostics, Inc. (a company developing blood tests for brain aneurysms), and in that capacity has had success in receiving multiple Phase I and Phase II SBIRs from the NIH and NSF.
Adnan Siddiqui - Dr. Adnan Siddiqui is a Professor of Neurosurgery and Radiology who joined University at Buffalo Neurosurgery in January 2007. He completed fellowship training in Interventional Neuroradiology, Cerebrovascular Surgery and Neurocritical Care from Thomas Jefferson University in Philadelphia. He completed his Neurosurgical residency at Upstate Medical University and received his PhD in Neuroscience from the University of Rochester and medical degree from Aga Khan University, Pakistan. The Neuroendovascular Research and Stroke Service is led by Dr. Siddiqui, who is proud to play a leadership role in UB's Department of Neurosurgery, which was ranked 7th in academic impact in North America by the Journal of Neurosurgery.

Jason Davies - Dr. Davies received his MD and PhD in Biophysics from Stanford. Dr. Jason Davies is an Assistant Professor of Neurosurgery and Biomedical Informatics at the State University of New York (SUNY) at Buffalo. Dr. Davies performs endovascular and surgical interventions on IAs at the Gates Vascular Institute (GVI) and has experience with national clinical trials, as well as cutting-edge research at the university. His active research interests focus on using bioinformatics tools to advance personalized medicine.

Kenneth Snyder - Dr. Snyder joined University at Buffalo Neurosurgery in 2011 after completing his fellowship training in endovascular neurosurgery with UB Neurosurgery and spent 6 months as a research fellow at the Barrow Neurological Institute. He completed his neurosurgical residency at UB and received his PhD in biophysics specializing in mechanoelectric transduction of cellular membranes. He is trained in all general neurosurgical procedures, including brain tumor, spine, and peripheral nerve surgery.

Elad Levy - Dr. Elad Levy is Professor of Neurosurgery and Radiology, L. Nelson Hopkins, MD Chairman of the Department of Neurological Surgery, Jacobs School of Medicine at Biomedical Sciences, at State University of New York at Buffalo. Dr. Levy is also the Co-Director, Gates Stroke Center and Cerebrovascular Surgery at Kaleida Health, Director of Endovascular Stroke Treatment and Research Medical Director of Neuroendovascular Services at Gates Vascular Institute (GVI). Dr. Levy has a national and global reputation in the field of neurovascular disease, and has co-authored over 300 peerreviewed publications, including several in the New England Journal of Medicine. Prior to his professorship at the University, Dr. Levy graduated from Dartmouth College and received his Doctor of Medicine degree with distinction from George Washington University.

Ciprian N. Ionita - Dr. Ciprian N. Ionita is an Assistant Professor in Biomedical Engineering and Neurosurgery at the University at Buffalo. He received his doctorate degree from the University at Buffalo. He is the director of the Endovascular Devices and Imaging Lab at the Canon Stroke and Vascular Research Center.

\section{Funding}

Kelsey Sommer, Ciprian Ionita, and Maxim Mokin were partially funded by a grant from NIH R21 NS109575-01. Mohammad Mahdi Shiraz Bhurwani, Vincent Tutino, Elad Levy, Kenneth Snyder, Adnan Siddiqui, and Jason Davies have no financial disclosures related to this research. 


\section{Availability of data and materials}

The datasets used and/or analyzed during the current study are available from the corresponding author on reasonable request.

\section{Declarations}

\section{Ethics approval and consent to participate}

The protocol for collection and the data analysis was approved by the Institutional Review Board (IRB) at the University at Buffalo. Informed consent was obtained from all human participants.

\section{Consent for publication}

Not applicable.

\section{Competing interests}

KNS - Shareholder: QAS.AI.

MMSB - Shareholder: QAS.AI

VT - Principal investigator: National Science Foundation Award No. 1746694 and NIH NINDS award R43 NS115314-0. Awardee of a Clinical and Translational Science Institute grant, a Cummings Foundation grant, and grants from the Brain Aneurysm Foundation. Co-founder: Neurovascular Diagnostics, Inc. Shareholder: QAS.AI.

AS - Research grant: NIH/NINDS 1R01NS091075 as a co-investigator for "Virtual Intervention of Intracranial Aneurysms". Financial interest/investor/stock options/ownership: Amnis Therapeutics, Apama Medical, Blink TBI Inc., Buffalo Technology Partners Inc., Cardinal Consultants, Cerebrotech Medical Systems, Inc. Cognition Medical, Endostream Medical Ltd., Imperative Care, International Medical Distribution Partners, Neurovascular Diagnostics Inc., Q'Apel Medical Inc., Rebound Therapeutics Corp., Rist Neurovascular Inc., Serenity Medical Inc., Silk Road Medical, StimMed, Synchron, Three Rivers Medical Inc., Viseon Spine Inc. Consultant/advisory board: Amnis Therapeutics, Boston Scientific, Canon Medical Systems USA Inc., Cerebrotech Medical Systems Inc., Cerenovus, Corindus Inc., Endostream Medical Ltd., Guidepoint Global Consulting, Imperative Care, Integra LifeSciences Corp., Medtronic, MicroVention, Northwest University-DSMB Chair for HEAT Trial, Penumbra, Q'Apel Medical Inc., Rapid Medical, Rebound Therapeutics Corp., Serenity Medical Inc., Silk Road Medical, StimMed, Stryker, Three Rivers Medical, Inc., VasSol, W.L. Gore \& Associates. Principal investigator/steering comment of the following trials: Cerenovus LARGE and ARISE II; Medtronic SWIFT PRIME and SWIFT DIRECT; MicroVention FRED \& CONFIDENCE; MUSC POSITIVE; and Penumbra 3D Separator, COMPASS, and INVEST. Shareholder: QAS.AI.

$J D$ - Research grant: National Center for Advancing Translational Sciences of the National Institutes of Health under award number KL2TR001413 to the University at Buffalo. Speakers' bureau: Penumbra; Honoraria: Neurotrauma Science, LLC. Shareholder/ownership interests: RIST Neurovascular. Shareholder: QAS.Al.

KS - Consulting and teaching for Canon Medical Systems Corporation, Penumbra Inc., Medtronic, and Jacobs Institute. Co-Founder: Neurovascular Diagnostics, Inc. Shareholder: QAS.AI.

EL - shareholder/Ownership interests: NeXtGen Biologics, RAPID Medical, Claret Medical, Cognition Medical, Imperative Care (formerly the Stroke Project), Rebound Therapeutics, StimMed, Three Rivers Medical. National Principal Investigator/Steering, QAS.AI.

Committees: Medtronic (merged with Covidien Neurovascular) SWIFT Prime and SWIFT Direct Trials. Honoraria: Medtronic (training and lectures). Consultant: Claret Medical, GLG Consulting, Guidepoint Global, Imperative Care, Medtronic, Rebound, StimMed. Advisory Board: Stryker (AlS Clinical Advisory Board), NeXtGen Biologics, MEDX, Cognition Medical, Endostream Medical. Site Principal Investigator: CONFIDENCE study (MicroVention), STRATIS Study_Sub I (Medtronic).

MM - Grants: Principal investigator NIH R21NS109575 Consultant: Medtronic, Cerenovus. Stock options: Serenity medical, Synchron, Endostream, VICIS, shareholder QAS.AI.

$\mathrm{Cl}$ - Equipment grant from Canon Medical Systems, support from the Cummings Foundation, NIH R21 grant, shareholder QAS.AI.

\section{Author details}

'Department of Biomedical Engineering, University at Buffalo, Buffalo, NY 14228, USA. ${ }^{2}$ Canon Stroke and Vascular Research Center, University at Buffalo, Buffalo, NY 14208, USA. ${ }^{3}$ Department of Neurosurgery, University at Buffalo, Buffalo, NY 14208, USA. ${ }^{4}$ Department of Pathology and Anatomical
Sciences, University at Buffalo, Buffalo 14208, USA. ${ }^{5}$ Department of Biomedical Informatics, University at Buffalo, Buffalo 14208, USA.

${ }^{6}$ Department of Neurosurgery and Brain Repair, University of South Florida, Tampa, FL 33620, USA.

Received: 9 July 2021 Accepted: 11 September 2021

Published online: 27 September 2021

\section{References}

1. Chepelev $L$, et al. Radiological Society of North America (RSNA) 3D printing Special Interest Group (SIG): guidelines for medical 3D printing and appropriateness for clinical scenarios. 3D Print Med. 2018;4(1):11.

2. Sommer K, Izzo RL, Shepard L, Podgorsak AR, Rudin S, Siddiqui AH, ... Ionita $\mathrm{CN}$. Design optimization for accurate flow simulations in 3D printed vascular phantoms derived from computed tomography angiography. In Medical Imaging 2017: Imaging Informatics for Healthcare, Research, and Applications. 2017 (Vol. 10138, p. 101380R). International Society for Optics and Photonics.

3. Sommer KN, et al. 3D printed cardiovascular patient specific phantoms used for clinical validation of a CT-derived FFR diagnostic software. In: Medical imaging 2018: biomedical applications in molecular, structural, and functional imaging: International Society for Optics and Photonics; 2018.

4. Shepard LM, Sommer KN, Angel E, Iyer V, Wilson MF, Rybicki FJ, et al. Initial evaluation of three-dimensionally printed patient-specific coronary phantoms for CT-FFR software validation. J Med Imaging. 2019;6(2):021603. https://doi.org/10.1117/1.JMI.6.2.021603.

5. Sommer KN, Shepard LM, Mitsouras D, lyer V, Angel E, Wilson MF, ... lonita CN. Patient-specific 3D-printed coronary models based on coronary computed tomography angiography volumes to investigate flow conditions in coronary artery disease. Biomed Phys Eng Express. 2020;6(4):045007.

6. Toth G, Cerejo R. Intracranial aneurysms: review of current science and management. Vasc Med. 2018;23(3):276-88. https://doi.org/10.1177/1358863 X18754693.

7. Meess KM, Izzo RL, Dryjski ML, Curl RE, Harris LM, Springer M, ... lonita CN. 3D printed abdominal aortic aneurysm phantom for image guided surgical planning with a patient specific fenestrated endovascular graft system. In Medical Imaging 2017: Imaging Informatics for Healthcare, Research, and Applications. 2017 (Vol. 10138, p. 101380P). International Society for Optics and Photonics.

8. El Sabbagh A, et al. The various applications of 3D printing in cardiovascular diseases. Curr Cardiol Rep. 2018;20(6):1-9. https://doi.org/10.1007/s1 1886-01 8-0992-9.

9. Tam MD, et al. 3D printing of an aortic aneurysm to facilitate decision making and device selection for endovascular aneurysm repair in complex neck anatomy. J Endovasc Ther. 2013;20(6):863-7. https://doi.org/10.1 583/13-4450MR.1.

10. Yang Y, Lei D, Huang S, Yang Q, Song B, Guo Y, et al. Elastic 3D-printed hybrid polymeric scaffold improves cardiac remodeling after myocardial infarction. Adv Healthc Mater. 2019;8(10):1900065. https://doi.org/10.1002/a dhm.201900065.

11. Milano EG, Capelli C, Wray J, Biffi B, Layton S, Lee M, et al. Current and future applications of 3D printing in congenital cardiology and cardiac surgery. Br J Radiol. 2019;92(1094):20180389. https://doi.org/10.1259/bjr.201 80389.

12. Tabaczynski J. Mechanical assessment of $3 D$ printed patient specific phantoms for simulation of minimally invasive image guided procedures. Buffalo: State University of New York; 2018.

13. Ionita CN, Mokin M, Varble N, Bednarek DR, Xiang J, Snyder KV, ... Rudin S. Challenges and limitations of patient-specific vascular phantom fabrication using 3D Polyjet printing. In Medical Imaging 2014: Biomedical Applications in Molecular, Structural, and Functional Imaging. 2014 (Vol. 9038, p. 90380M). International Society for Optics and Photonics.

14. Mokin M, Wagas M, Setlur Nagesh SV, Karkhanis NV, Levy El, lonita CN, et al. Assessment of distal access catheter performance during neuroendovascular procedures: measuring force in three-dimensional patient specific phantoms. J Neurointervent Surg. 2019;11(6):619-22. https:// doi.org/10.1136/neurintsurg-2018-014468.

15. Sherman JR, Rangwala HS, Ionita CN, Dohatcu AC, Lee JW, Bednarek DR, .. Rudin S. Investigation of new flow modifying endovascular image-guided interventional (EIGI) techniques in patient-specific aneurysm phantoms (PSAPs) using optical imaging. In Medical Imaging 2008: Visualization, 
Image-Guided Procedures, and Modeling. 2008 (Vol. 6918, p. 69181V). International Society for Optics and Photonics.

16. Steinman DA, Hoi Y, Fahy P, Morris L, Walsh MT, Aristokleous N, et al. Variability of computational fluid dynamics solutions for pressure and flow in a giant aneurysm: the ASME 2012 summer bioengineering conference CFD challenge. J Biomech Eng. 2013;135(2):021016. https://doi.org/10.111 5/1.4023382

17. Campbell BC, et al. Safety and efficacy of solitaire stent thrombectomy: individual patient data meta-analysis of randomized trials. Stroke. 2016;47(3): 798-806. https://doi.org/10.1161/STROKEAHA.115.012360.

18. Turk AS III, Siddiqui A, Fifi JT, de Leacy RA, Fiorella DJ, Gu E, et al. Aspiration thrombectomy versus stent retriever thrombectomy as first-line approach for large vessel occlusion (COMPASS): a multicentre, randomised, open label, blinded outcome, non-inferiority trial. Lancet. 2019;393(10175):9981008. https://doi.org/10.1016/S0140-6736(19)30297-1.

19. Jauch EC, Saver JL, Adams HP Jr, Bruno A, Connors JJ, Demaerschalk BM, et al. Guidelines for the early management of patients with acute ischemic stroke: a guideline for healthcare professionals from the American Heart Association/American Stroke Association. Stroke. 2013;44(3):870-947. https:// doi.org/10.1161/STR.0b013e318284056a.

20. Goyal M, Menon BK, van Zwam WH, Dippel DWJ, Mitchell PJ, Demchuk $\mathrm{AM}$, et al. Endovascular thrombectomy after large-vessel ischaemic stroke: a meta-analysis of individual patient data from five randomised trials. Lancet. 2016;387(10029):1723-31. https://doi.org/10.1016/50140-673 6(16)00163-X.

21. Mokin M, Setlur Nagesh SV, Ionita CN, Levy El, Siddiqui AH. Comparison of modern stroke thrombectomy approaches using an in vitro cerebrovascular occlusion model. Am J Neuroradiol. 2015;36(3):547-51. https://doi.org/10.31 74/ajnr.A4149

22. Mokin M, Setlur Nagesh SV, lonita CN, Mocco J, Siddiqui AH. Stent retriever thrombectomy with the cover accessory device versus proximal protection with a balloon guide catheter: in vitro stroke model comparison. J Neurointervent Surg. 2016;8(4):413-7. https://doi.org/10.1136/neurintsurg-2 014-011617.

23. Yeniçeri IÖ, Çullu N, Deveer M, Yeniçeri EN. Circle of Willis variations and artery diameter measurements in the Turkish population. Folia Morphol (Warsz). 2017;76(3):420-5. https://doi.org/10.5603/FM.a2017.0004.

24. Shepard L, Sommer K, Izzo R, Podgorsak A, Wilson M, Said Z, ... Ionita CN. Initial simulated FFR investigation using flow measurements in patientspecific 3D printed coronary phantoms. In Medical Imaging 2017: Imaging Informatics for Healthcare, Research, and Applications. 2017 (Vol. 10138, p. 101380S). International Society for Optics and Photonics.

25. Sommer KN, et al. Method to simulate distal flow resistance in coronary arteries in 3D printed patient specific coronary models. 3D Print Med. 2020; 6(1):1-10.

26. Tabaczynski JR, Stoll T, Shepard L, Siddiqui MI, Karkhanis NV, Sommer K, ... lonita CN. Use of patient specific 3D printed (3DP) neurovascular phantoms for mechanical assessment of devices used in image guided minimally invasive procedures. In Medical Imaging 2018: Imaging Informatics for Healthcare, Research, and Applications. 2018 (Vol. 10579, p. 105790K). International Society for Optics and Photonics.

27. Sommer KN, Bhurwani MMS, Mokin M, lonita CN. Evaluation of challenges and limitations of mechanical thrombectomy using 3D printed neurovascular phantoms. In Medical Imaging 2021: Imaging Informatics for Healthcare, Research, and Applications. 2021 (Vol. 11601, p. 116010B). International Society for Optics and Photonics.

28. Duffy S, Farrell M, McArdle K, Thornton J, Vale D, Rainsford E, et al. Novel methodology to replicate clot analogs with diverse composition in acute ischemic stroke. J Neurointervent Surg. 2017;9(5):486-91. https://doi.org/1 0.1136/neurintsurg-2016-012308.

29. Ionita CN, Hoi Y, Meng H, Rudin S. Particle image velocimetry (PIV) evaluation of flow modification in aneurysm phantoms using asymmetric stents. In Medical Imaging 2004: Physiology, Function, and Structure from Medical Images. 2004 (Vol. 5369, pp. 295-306). International Society for Optics and Photonics.

30. Ionita CN, Suri H, Nataranjian S, Siddiqui A, Levy E, Hopkins NL, ... Rudin S. Angiographic imaging evaluation of patient-specific bifurcation-aneurysm phantom treatment with pre-shaped, self-expanding, flow-diverting stents: feasibility study. In Medical Imaging 2011: Biomedical Applications in Molecular, Structural, and Functional Imaging. 2011 (Vol. 7965, p. 79651H). International Society for Optics and Photonics.
31. Schafer S, Hoffmann KR, Noël PB, lonita CN, Dmochowski J. Evaluation of guidewire path reproducibility. Med Phys. 2008;35(5):1884-92. https://doi. org/10.1118/1.2903430.

32. Cloonan AJ, et al. 3D-printed tissue-mimicking phantoms for medical imaging and computational validation applications. 3D Print Additive Manufact. 2014;1 (1):14-23.

33. de Galarreta SR, Cazón A, Antón R, Finol EA. Abdominal aortic aneurysm: from clinical imaging to realistic replicas. J Biomech Eng. 2014;136(1): 014502. https://doi.org/10.1115/1.4025883.

34. Biglino G, Capelli C, Wray J, Schievano S, Leaver LK, Khambadkone S, et al. 3D-manufactured patient-specific models of congenital heart defects for communication in clinical practice: feasibility and acceptability. BMJ Open. 2015;5(4):e007165. https://doi.org/10.1136/bmjopen-2014-007165.

\section{Publisher's Note}

Springer Nature remains neutral with regard to jurisdictional claims in published maps and institutional affiliations.
Ready to submit your research? Choose BMC and benefit from:

- fast, convenient online submission

- thorough peer review by experienced researchers in your field

- rapid publication on acceptance

- support for research data, including large and complex data types

- gold Open Access which fosters wider collaboration and increased citations

- maximum visibility for your research: over $100 \mathrm{M}$ website views per year

At BMC, research is always in progress.

Learn more biomedcentral.com/submissions 